\title{
Философия
}

\author{
УДК 130.2:316.77(045)
}

\section{И.А. Латыпов}

\section{МУЛЬТИФРАКТАЛЬНОСТЬ СЕТЕВЫХ МЕДИАКОММУНИКАЦИЙ В ИНФОРМАЦИОННОЙ ЦИВИЛИЗАЦИИ: ФИЛОСОФСКИЙ АСПЕКТ}

\begin{abstract}
В статье рассматривается один из актуальных философских вопросов, касающихся оценки перспектив развития сетевых медиакоммуникаций в информационной цивилизации. Анализ развития сетевых медиакоммуникаций формирует контуры нового предметного поля не только конкретно социально-философских или культурологических, но и междисциплинарных исследований феномена мультифрактальности в целом. Рассмотрение этих мультифрактальных перспектив с точки зрения социальной философии культуры информационной цивилизации оказывается в статусе междисциплинарных исследований в сфере философских наук. В статье формируется дискурс мультифрактальных медиакоммуникаций в глобальном сетевом пространстве. Медиакоммуникации в данной работе определяются как вид социальных коммуникаций в медиапространстве.

Основная проблема исследования сводится к следующему вопросу: возможно ли в философском контексте охарактеризовать вопрос о мультифрактальности сетевых медиакоммуникаций? Цель данного исследования анализ философского аспекта мультифрактальности сетевых медиакоммуникаций в информационной цивилизации. Объект исследования - многообразие процессов развития социальных коммуникаций, связанных с перспективами современных медиакоммуникаций. Ключевая гипотеза, проверяющаяся в исследовании, заключается в том, что разработка философской теории глобальных сетевых медиакоммуникаций может носить фракталоподобный характер. Понятие мультифрактальности определяется как процесс и результат конструирования сложных самоподобных структур на основе последовательного использования нескольких алгоритмов создания различных фракталов.
\end{abstract}

Ключевые слова: фрактал, мультифрактальность, сетевая коммуникация, медиакоммуникации, философия, информационная цивилизация.

DOI: $10.35634 / 2412-9550-2020-30-4-333-343$

\section{Введение}

Обсуждение темы, заявленной в данной статье, с возможностью инициирования соответствующей дискуссии является актуальным, с одной стороны, в связи с четырьмя месяцами удаленной (дистанционной) работы, убедившими многих в возможности и даже необходимости развития сетевых коммуникаций в информационной цивилизации. С другой стороны, актуальность определяется тем, что вполне позитивный и конструктивный возврат активно действующего субъекта в гуманитарные науки и обществознание в целом и в социально-философскую теорию в частности зачастую сопровождается недооценкой роли научного знания и каких-либо попыток объективного суждения об основных тенденциях цивилизационного развития.

Этот возврат человека как активно действующего субъекта стал неизбежным после «заката» постмодернизма. Но недооценка роли научного знания в комплексе российских социогуманитарных наук случается, когда некоторые российские исследователи проводят поспешное обобщение современного кризиса науки в РФ до кризиса рациональной науки в целом.

По мнению этих исследователей, «суть этого кризиса заключается в гиперболизации значения науки для жизни человека» [6. С. 82]. При этом, не замечая некоторых несообразностей, те же исследователи пытаются предлагать новые научные подходы к теории массовой коммуникации. К счастью, они это уже не считают гиперболизацией значения науки в своей работе.

Кризис же рациональной науки действительно периодически случается, но по другой причине. Это происходит при переходе от так называемой нормальной науки к «революционной» или «экстраординарной» науке (по терминологии Томаса Куна) в процессе глобальных научных революций.

Впрочем, и в мировой науке уже более девяти десятков лет после открытия соотношения неопределенностей Гейзенберга сохраняет свою остроту вопрос о переоценке роли познающего субъекта. Но это не означает полного отказа от возможности объективного суждения о реальности в целом и о 
социальной реальности в частности. Это лишь означает необходимость поиска золотой середины в анализе места и значения познающего субъекта в различных попытках объективных суждений, в том числе и о цивилизационных трендах.

Кроме того, на удаленной дистанционной работе активные действия субъекта могут проявляться в основном в сетевых коммуникациях, значение которых в информационной цивилизации постоянно возрастает. А более или менее продолжительные работа или учеба на дому с неизбежностью будут периодически востребованы для значительной части населения.

Данная работа в настоящий момент необходима и для обобщения и систематизации прежних промежуточных или предварительных результатов исследований автора сетевых медиакоммуникаций в информационной цивилизации, а также для оценки перспектив и возможностей социогуманитарных наук в области мультифрактальных сетевых структур.

Постановка же проблемы исследования сводится к возможности охарактеризовать вопрос о мультифрактальности сетевых медиакоммуникаций в информационной цивилизации в общем философском виде.

\section{Степень изученности проблемы}

Изучение различных проблем информационных отношений в целом проводили многие исследователи: Г. Бейтсон, Л. Бриллюэн, Н. Винер, В.З. Коган, А.Н. Колмогоров, В.А. Копылов, А.В. Костров, Н. Луман, Г.Г. Почепцов, С.П. Расторгуев, А. Тьюринг, К. Шеннон, Г. Шиллер, Н. Шульман и др.

Советские и российские философы исследовали информационные отношения первоначально на основе ленинской теории отражения и рассмотрения информации как отраженного многообразия мира (А.Д. Урсул, А.П. Суханов и др.) или в постепенном уточнении подхода с перестроечной поры и все большем дистанцировании от вышеупомянутой трактовки информации (В.И. Кашперский, Р.Ф. Абдеев, А.И. Ракитов, Ю.А. Шичалин, С.К. Шайхитдинова, И.И. Юзвишин, Ю.В. Яковец и др.).

Различные аспекты и этапы изменения подходов в обществоведческом осмыслении социального развития, формирования постиндустриального и/или информационного общества исследовали Д. Белл, В.Л. Иноземцев, М. Кастельс [9], Й. Масуда, Ф. Сколимовски, Т. Стоуньер, О. Тоффлер, А. Турен, Ю. Хайяши и др.

Медиакоммуникации в рамках виртуализации социальной реальности на основе информационных технологий с различных точек зрения исследуются Ж. Бодрийяром, П. Вирилио, А.Б. Долгиным, С. Жижеком, Р.Н. Каримовым [8], М. Кастельсом [9], Г.М. Маклюэном [17], М.К. Рыклиным, В.В. Савчуком [19] и др.

Основы теории аутопоэтических (самовоспроизводящихся и самодостраивающихся) систем заложили У. Матурана и Ф. Варела.

Проблема мультифрактальности информационных отношений в сетевом пространстве с философской точки зрения уже ставилась автором в [11-14; 22]. В работе [12] есть и философский анализ различных подходов к исследованию множественных алгоритмов преобразования самоподобных (фрактальных) систем информационных отношений в интернет-пространстве.

Основателем теории фракталов и мультифракталов является Б. Мандельброт [23].

Логико-философское осмысление фрактальной метафизики является заслугой В.В. Тарасенко.

Объектом данного исследования являются социальные процессы и общественные отношения, связанные с мультифрактальными перспективами развития современных сетевых медиакоммуникаций.

Предмет исследования - мультифрактальность медиакоммуникаций сетевого общества как современное социальное явление.

Цель работы - философский анализ мультифрактальности сетевых медиакоммуникаций в информационной цивилизации.

Достижение поставленной цели предполагает решение таких задач, как:

- обсуждение основ мультифрактальной теории информационной цивилизации;

- рассмотрение мультифрактальных изменений российских региональных обсуждений проблем самоидентичности, ведущихся в социальных сетях в Рунете;

- обобщение сетевых медиакоммуникаций с фрактальной точки зрения. 
Мультифрактальность сетевых медиакоммуникаций в информационной цивилизации...

\section{Методы исследования}

В данной междисциплинарной работе используется методологическая концепция полисубъектной социальности Уральской философской школы, модифицировавшая классический деятельностный подход для современных неравновесных социальных процессов одновременного взаимодействия многих по-разному меняющихся субъектов и развивающихся социальных систем (по Кемерову В.Е. [10]). Классический же конструктивистский подход к анализу социальной реальности системы массмедиа разработал Никлас Луман (см. [16]).

Кроме этого, избран такой подход к определению медиакоммуникации, который трактует их в качестве вида коммуникаций в медиапространстве как части социального пространства. Тем самым медиакоммуникации понимаются как вид социальных коммуникаций в медиасреде общественного производства и производства информации.

К методам исследования относятся сравнительный анализ и включенное неструктурированное наблюдение в качестве участника, модератора и (или) администратора различных групп или сообществ в социальных сетях в Рунете с точки зрения философии повседневности. В работе проводились сравнительный анализ и включенное неструктурированное наблюдение за осознанием или недооценкой проблем идентичности в целом более 3000 информантов в «Фейсбуке», проблем вузовской идентичности в группе Novosibirsk State University (NSU) (более 2000 участников) [4] в «Фейсбуке» и в российской сети ВКонтакте в группе «ПРиИСК» (более 900 участников) [2], а также за некоторыми другими группами, например этноцентрированными и региональными группами в «Фейсбуке» [3] и в «Одноклассниках» [20].

В данной статье будет раскрыт обществоведческий аспект проблемы направления изменений российских региональных обсуждений проблем самоидентичности в российских социальных медиасетях.

Исследуемый материал. К основным данным относятся: совокупность наблюдений за региональными полемическими обсуждениями проблем самоидентичности в социальных сетях в Рунете, не касающихся политических аспектов идентичности.

В результате включенного неструктурированного наблюдения выявляется проблема кризиса идентичности и идентификации «чужих» и «своих», по крайней мере в некоторых российских регионах, и возможность возрождения классовой идентичности.

\section{Наброски мультифрактального понимания сетевых медиакоммуникаций информационной цивилизации}

Чтобы не повторяться, необходимо кратко отметить приоритет и неоценимый вклад Бенуа Мандельброта в разработке и формировании теории фракталов, в анализе перспектив применения фрактального подхода к социально-экономическим процессам и в разработке теоретических основ теории мультифракталов [23].

Сетевые медиакоммуникации же образуют фракталоподобную систему.

К сетевым медиакоммуникациям можно отнести и известные социальные медиасети, и чаты, и форумы, и многие другие формы и медиумы, необходимые и, возможно, привычные для передачи информации и сетевых коммуникаций онлайн. Система сетевых и традиционных медиакоммуникаций определенного региона формирует региональную медиасистему. Аналогично формируются национальные, субглобальные и глобальная медиасистемы. В целом конструирование медиасистем различного уровня сводится к конструированию каких-либо систем вообще.

«Общая теория систем примечательна тем, что вполне устраивает как математиков, так и представителей гуманитарной мысли. Понятие «системы» для описания объектов оказывается универсальным приемом» [6. С. 88]. И некоторые представители гуманитарной мысли совершенно справедливо и оправданно используют общую теорию систем для анализа фрактальных систем, хоть и допускают некоторые устаревшие суждения о естественно-научном контексте теории диссипативных систем.

В самом деле, уже устарело суждение: «Согласно второму закону термодинамики, всякая система стремится к росту энтропии. Иными словами, физические микропроцессы сами по себе ведут к отдаленной по времени, но неизбежной, как считается, тепловой смерти Вселенной» [6. С. 89]. 
Действительно, космологическая концепция тепловой смерти была общепризнанной лишь в классической термодинамике Вселенной, отвергнутой в силу открытости расширяющегося универсума (хотя и остаются вопросы о перспективах ускоряющегося расширения Вселенной). Все же вопросы обоснованности концепции тепловой смерти Вселенной на современном этапе уводят в сторону от предметного поля исследования, хотя и касаются основ общей теории систем.

Нас интересуют прежде всего системы сетевых и традиционных медиакоммуникаций. Поэтому, кратко отметив некоторые нюансы общей теории систем, перейдем к анализу социальных систем.

В общем виде конструирование каких-либо медиасистем является разновидностью конструктивистской деятельности в рамках различных социальных систем. Классиком конструктивистского подхода в исследованиях реальности социальной системы медиакоммуникации был Н. Луман.

Концепция же полисубъектной социальности трактует развивающееся и меняющееся на наших глазах информационное общество как результат одновременных разнонаправленных индивидуальных и коллективных усилий огромного количества людей, коллективов, социальных групп с различиями их мотивации, интересов и целей [10].

Социальные системы информационного общества с неизбежностью оказываются полисубъектными в силу бурного роста и усложнения систем сетевых коммуникаций в интернет-пространстве.

Рассмотрим их с точки зрения теории фракталов как современного направления междисциплинарных исследований, формирующего целостную картину мира и имеющего междисциплинарный и метапредметный характер.

Одно из основных свойств, объединяющих все идеальные фракталы, - это точное повторение самого себя на любом масштабном уровне (самоподобие). Другими словами, самоподобный объект в точности или приближенно совпадает с частью себя самого, то есть целое имеет ту же форму, что и одна или более частей [15]. Реальные же структуры далеки от идеала и чаще являются фракталоподобными.

Рассмотрение социальных систем информационного общества как фракталоподобных систем основывается на ключевом свойстве самоподобия, когда подсистема в качестве части подобна целой метасистеме (т. е. не обязательно является точным повторением), а различные элементы этой подсистемы сами оказываются подобными для подсистем более низкого уровня, подобными всей системе в целом.

Самоподобие интернет-пространства фиксируется многими исследованиями структуры глобальной сети, что характеризует интернет-пространство как фракталоподобную систему. Тогда современная социальность сетевой цивилизации оказывается не только полисубъектной, но и фракталоподобной.

Структуры Рунета же оказываются подобными целой метасистеме глобального интернетпространства. Но это подобие не означает тождественности, поскольку Рунет явно отличается от китайского, испаноязычного, японского, арабоязычного или индийского сегментов интернетпространства. Поэтому статья нацелена на анализ мультифрактальности сетевых медиакоммуникаций, а не фрактальности.

Дело в том, что мультифрактальные (и подобные им) структуры конструируются в процессе неоднократно повторяющихся изменений, замены и усложнения нескольких алгоритмов создания разных фракталов. В силу этого метасистема глобального интернет-пространства формируется из многих сегментов интернет-пространства, в том числе и не упомянутых выше (например, португалоязычного или франкоязычного, не говоря уже об англоязычном «костяке» Сети). В свою очередь, структуры Рунета конструируются и самоорганизуются из структур домена «.ru», домена «.su» (ocтавшегося в наследство от советской поры) и кириллического домена «.рф». И так далее.

Термин «мультифрактальность» выражает процесс и результат конструирования сложных самоподобных структур на основе последовательного использования нескольких алгоритмов создания различных фракталов. Понятия же фракталов и фрактальности, ставшие уже классическими, заимствованы из теории фракталов Бенуа Мандельброта. В частности, фрактальность является характеристикой такой системы, которая состоит из различных частей, по определенным критериям подобных целой системе.

Методология мультифрактальности в анализе медиакоммуникаций характеризуется прежде всего тем, что, несмотря на их стремительные конвергентные изменения и бурный рост в последние десятилетия, распределение сообщений в сфере медиакоммуникаций по частоте цитирований и ссылок, а также распределение по таким показателям, как источники, авторы, тематика, ключевые слова, практически не меняют своей формы. 
Мультифрактальность сетевых медиакоммуникаций в информационной цивилизации...

В самом деле, к основным законам, отражающим самоподобие современных научных медиакоммуникаций для распределения, например, по ключевым словам, можно отнести закон Зипфа. В данном законе порядковый номер частоты вхождения слова в некотором тексте (в общем списке частот для этого текста) называется рангом этой частоты.

«Джордж Зипф (George K. Zipf...) в результате проведения исследований языка определил, что все созданные человеком тексты построены по единым правилам - слова с большим количеством букв встречаются в тексте реже коротких слов. Без закона Зипфа, опубликованного в 1949 году, сегодня не обходится ни одна система автоматического поиска информации. ... Ученый описал обнаруженную им закономерность распределения слов в текстах на английском языке:

- небольшое количество слов, таких как the, and в английском языке, имеют очень высокий ранг;

- среднее количество слов имеет средний ранг;

- большое количество слов имеет очень низкий ранг.

Исследования показывают, что наиболее значимые слова лежат в средней части графика... Слова, которые попадаются слишком часто, в основном оказываются предлогами, местоимениями, в английском - артиклями и т. п. Редко встречающиеся слова тоже в большинстве случаев не имеют решающего смыслового значения. Если пользователь будет делать запрос информационно-поисковым системам с учетом сказанного, то он будет получать более релевантный список ссылок. От того, как будет выставлен диапазон значимых слов, зависит многое. Поставь широко - нужные термины потонут в море вспомогательных слов; установи узкий диапазон - потеряешь смысловые термины» [14. С. 22].

Этот закон верен не только для научных медиакоммуникаций, но и для поисковых запросов по различным ключевым словам, характеризующим актуальные социально-политические, экономические, социально-психологические, познавательные или образовательные проблемы, а также вопросы философии, культурологии, этничности и т. п.

Действительно, «каждая поисковая система решает проблему по-своему, руководствуясь общим объемом текста, специальными словарями и т. п. Проще говоря, любой документ в базах данных маркируется поисковой системой таким перечнем значимых слов. Если сравнить списки значимых и ключевых слов (которые требуются теперь в любой весомой научной статье), то они пересекаются, но не обязательно совпадают. ... Характеристики популярности узлов Интернет также отвечают законам Зипфа. С другой стороны, этот закон позволяет безошибочно отличить текст, написанный человеком, от созданного программным агентом псевдотекста. При этом даже не нужно знать язык, на котором написан текст, - достаточно знать только морфологию. Используя один только этот инструмент, можно существенно продвинуться в решении проблемы информационного «мусора», который заполняет большую часть Web-пространства» [14. C. 22].

Неоднократно публиковались работы, из которых следует, что подобный тип распределения, помимо лингвистики, характерен и для объектов в области социологии, науковедения и т. п.

\section{Обсуждение}

Идентификация и разграничение «чужих» и «своих» ранее всегда была жизненно важной для всех социальных общностей. Но в современной цивилизации это разграничение часто оказывается подверженным критике, что проявляется и в региональной полемике в социальных сетях, даже если споры дистанцируются от политики. Обществоведческий анализ этих изменений востребован именно в настоящий момент, что характеризует актуальность исследуемой проблемы.

Идентичность человека проблематизировалась Платоном, Диогеном и Аристотелем. Показательны дискуссии по поводу ненаучного определения Платона, или уже более строгого аристотелевского понимания «политического животного», или более позднего научного определения Ноmo sapiens как «человека разумного».

Проблема классовой идентичности исследовалась в марксистской социальной теории многими обществоведами.

Постмодернистская констатация утраты персональной идентичности человека постепенно сменяется «возвращением субъекта» в социальную теорию (по А. Турену и В.Е. Кемерову).

Мануэль Кастельс в своих работах отмечал уже значимость проблемы идентичности в информациональном обществе в целом. Приведем лишь некоторые примеры злободневных тем сетевых медиакоммуникаций разного масштаба на разных уровнях общности. 
В настоящее время довольно долго вне конкуренции были те изменения глобальных, российских или региональных обсуждений проблем самоидентичности, ведущихся в социальных сетях, которые связаны с дискуссиями в контексте ситуации с COVID-19, с поиском вакцины и проблемами самоизоляции. В самом деле, идентификация себя в качестве больного ли, здорового ли, подверженного риску заражения (или нет), в ситуации пандемии обсуждалась и по-прежнему обсуждается уже в течение продолжительного времени в глобальном масштабе. Как следствие социальноэкономических проблем, вызванных пандемией, обострились проблемы идентичности и в межрасовых конфликтах в североамериканском обществе. Также это ярко проявилось в реальных и виртуальных дискуссиях по поводу движения Black lives matter!

Совершенно другие аспекты проблемы идентичности, наряду со многими другими проблемами, проявлялись и проявляются в развитии индийского сегмента интернет-пространства. В частности, индийский премьер-министр Нарендра Моди в честь праздника Международного женского дня (8.03.2020 г.) через свои «премьерские» аккаунты дал возможность семи индийским женщинам рассказать о себе и своих идеях, продвигая их в Сети. Предложение необычное и привлекательное для некоторых блогеров, т. к. у «премьерских» аккаунтов в трех популярных глобальных сетях - «Твиттере», «Фейсбуке» и «Инстаграме» - примерно (или почти) по полусотне миллионов подписчиков [7. С. 14].

Это немного по-другому выглядит в контексте того, что еще совсем недавно сохранялись обычаи сати как ритуального самосожжения вдов (даже в начале XXI века) и до сих пор изредка выявляющиеся случаи реализации свадебной традиции даори (даури) по поводу выбора родителями брачных партнеров для своих детей, приданого, расходов по организации свадьбы, иногда и доведения невестки свекровью до самоубийства (в случае отказа стороны родственников молодой жены возместить расходы, связанные с даори) и т. п.

Наряду с упомянутыми изменениями можно отметить постепенное распространение такого слогана, как "Proudly Indian!", непосредственно связанного с национальной идентичностью в стране, насчитывающей около тысячи разных языков и народов. В самом деле, наречие Proudly можно переводить, например, как «гордо».

Тем не менее вышеупомянутые аспекты в настоящий момент, как и во многих других регионах планеты, вытеснены различными факторами, связанными с ухудшением эпидемиологической обстановки в ходе распространения COVID-19.

В ходе самоизоляции сместился вектор споров по поводу размывания среднего класса или вообще его существования в РФ, снижения роли пролетариата в ходе экономического кризиса, а также изменений статуса интеллигенции (например, резко возросла общественная оценка значимости медиков и возникла неоднозначность в оценке дистанционной преподавательской деятельности).

Но в сегменте интернет-пространства, связанном с союзом России и Белоруссии, реализуются и другие тенденции.

Например, белорусские и российские сетевые обсуждения и дискуссии по поводу массовых протестов и креативных оппозиционных акций в Минске, Барановичах, Бресте, Витебске, Гомеле, Могилёве и некоторых других городах Беларуси в связи с недавними выборами президента соседней с нами страны выявили различные проблемы идентичности белорусов, по крайней мере отчасти.

В российских же регионах обсуждения проблемы самоидентичности также меняются прямо на глазах. Изменения, которые происходят в российских региональных обсуждениях этой проблемы в социальных сетях, имеют определенные сходства и отличия в сопоставлении с глобальными тенденциями проблем идентичности и самоидентичности.

К примеру, недавние региональные и федеральные обсуждения массовых протестов в Хабаровске (и некоторых других городах РФ) по поводу снятия краевого губернатора С.И. Фургала фактически выявили проблему идентичности хабаровчан, наряду со многими другими проблемами.

С возможным кризисом идентичности могут быть связаны по крайней мере некоторые проявления ксенофобии в Рунете. В мини-опросе, проведенном в одной из групп ВКонтакте, выявляется, что опасающихся роста числа проявлений ксенофобии в Рунете больше, чем считающих ситуацию неизменной или надеющихся на снижение напряженности в этом отношении. В условиях самоизоляции и второй (возможной на момент написания статьи) волны пандемии, на взгляд автора, вряд ли уменьшится число проявлений ксенофобии, в том числе в Рунете. Как на правдоподобное пояснение можно сослаться на закон термодинамики: в замкнутой системе энтропия (мера хаотичности) растет или остается на прежнем уровне. Аналогично: в самоизоляции мера хаотичности не убывает. Други- 
Мультифрактальность сетевых медиакоммуникаций в информационной цивилизации...

ми словами, раздражение, агрессивность, деструктивность и т. п. не уменьшаются. А вот будет ли расти число проявлений ксенофобии - это уже другой вопрос. Один из участников опроса оставил открытым вопрос о том, будет ли расти число проявлений ксенофобии, - со следующим пояснением:

1) надо отделять непосредственно ксенофобские хейтерство и флейминг в Рунете вообще, с одной стороны, от отражения в Рунете офлайновой ксенофобии, с другой стороны;

2) те, кто считает, что число проявлений ксенофобии будет расти, идеализировали или до сих пор идеализируют прежнюю ситуацию с ксенофобией в РФ (может, они просто не сталкивались с этим явно или не обращали внимания).

Хотя, конечно, в вышеупомянутом первом пункте полностью проводить отделение невозможно и бессмысленно. Можно просто отдавать себе отчет в том, что это немного разные вещи. Кроме того, один из участников опроса утверждает по поводу возможного роста число проявлений ксенофобии: «Раньше мне казалось, что уже почти некуда было расти. Сейчас выясняется, что пока есть куда расти».

Некоторые сложности идентификации «чужих» и «своих» выявляются и в спорах о 100-летии ТАССР и о 30-летии Декларации суверенитета Татарстана. Отчасти это связано с вопросом об этимологии термина «татары» и с этнической идентичностью поволжских, астраханских, крымских и сибирских татар, с одной стороны, и с дифференциацией татар и кряшенов и т. д., с другой стороны. Дело в том, что есть несколько групп в татарском мире: казанская (поволжская), кряшенская, астраханская, сибирская, крымская. Хакасов называют енисейскими татарами. До революции азербайджанцев звали кавказскими татарами и т. д.

Наряду с многочисленными комментариями на татарском языке (или так называемом сетевом «албанском»), в том числе и с ненормативной лексикой, встречается много аргументов на русском языке, вполне литературном. Например, часто цитируется Л.Н. Гумилев, в частности: «Ради истины, а не ради псевдонаучной, политической или какой-то другой конъюнктуры я, русский человек, всю жизнь защищаю татар от клеветы» [18].

Впрочем, ненормативная лексика встречается с обеих (и даже со многих) сторон. В том числе ненормативная лексика встречается в бытовом национализме тех участников сетевых дискуссий, кто с детства привык татарина называть «нерусью», выходцев из Средней Азии с детства привык обзывать «чурками». Хотя этот бытовой национализм не сегодня возник и не с началом пандемии. Кто-то из прежнего поколения называл Виктора Цоя «япохой», казахов называл «налимами» и т. д. Прежнего советского интернационализма уже нет, а мультикультурализм и не мог прижиться, хотя многие цитаты Гумилева Л.Н. вполне мультикультурны (а вопрос о возможности татарского мультикультурализма ставится только на уровне межличностных коммуникаций). Отношение же прежних поколений к инородцам и иноверцам и еще более ранние проблемы просто выходят за рамки данного исследования. Тем более уведут в сторону и многочисленные стереотипы, ярлыки и т. п.

Но последние три года татары и русские (прежде всего в Татарстане) особенно бурно и жестко спорят по поводу изучения родного языка. Если три года назад татары нечасто инициировали подобные споры (тогда в Татарстане чаще вопрос о естественном отсутствии желания изучать татарский язык поднимался русскими семьями), то сейчас уже такие проблемы поднимаются татарами, даже в некоторых случаях двуязычия и мультилингвизма. И это тоже можно трактовать (уже с другой точки зрения) в качестве естественной реакции, хоть и отсроченной по времени.

Эти вопросы встают и в других регионах. И даже вполне толерантный мордвин (Евгений Маркачев - министр образования Мордовии в 2015-2017 гг.) констатирует проблему потенциального ускорения процессов вымирания миноритарных языков. В редакции В. Ворсобина (наполовину мордвина, наполовину русского) мысль выражается так:

«Два урока в неделю... - вздохнул ... эрзянин... - Дело хорошее. Но знаешь, на что это похоже? Идет нищий - дай ему хлеба. Он, конечно, все равно умрет. Но хотя бы не перед тобой...» [1].

Нет ничего удивительного в том, что многие участники сетевых дискуссий часто упоминают Красную книгу исчезающих языков. При этом некоторые российские политики своими популистскими высказывания пытаются защитить русских граждан или жителей Прибалтики, Украины и других постсоветских республик, на деле совершая некоторые действия в отношении коренных народов РФ, схожие с теми, которые совершались или совершаются некоторыми прибалтийскими и украинскими политиками в отношении русских, живущих за пределами РФ.

Естественно, что этот популизм льет воду на мельницу тех масс, кому с детства было или до сих пор лень изучать какие-либо нерусские языки, кроме английского. Но многие участники сетевых 
дискуссий часто сравнивают этот популизм с «двойной бухгалтерией», поскольку для коренных народов РФ добровольное (т. е. необязательное) изучение родного языка оказывается чем-то более низким по сравнению с пением, физкультурой, так называемой «окружайкой» и другими обязательными предметами, сколько бы на них ни отводилось часов. Здесь используются лексика и содержание «постов» и комментариев настолько многих участников сетевых дискуссий, что выделять кавычками и снабжать ссылками на сетевой адрес этих материалов просто нереально (к тому же многие сетевые материалы исправляются или даже удаляются в ходе бурных споров).

Сложно сохранять нейтральность и научную объективность в ситуации жесткой сетевой дискуссии, наподобие «холивара» (англ. holy war - «священная война»). К тому же научный этос обществоведа и гуманитария вполне совместим с ценностными суждениями. Для сравнения: широко известный философ Жак Деррида (труды которого по праву можно относить к культурному наследию Франции) аналогичным образом упоминал проблемы бытового национализма как среди, так и в отношении евреев в Алжире и во Франции в различные периоды. Антисемитские же взгляды встречались и встречаются у довольно большого числа даже крупных (в своей области знания) ученых.

Но вышеупомянутые ценностные суждения усложняются в связи с необходимостью дифференциации «своих среди чужих» и «чужих среди своих». Требуются своего рода аналоги древнего «шибболета» устных коммуникаций, например для современных споров уже в сетевых коммуникациях. Можно предположить, что одним из пробных камней для споров по проблемам этничности может быть проблема сопоставления конструктивизма и примордиализма, уводящая в сторону от исследуемой темы.

В другом соседнем регионе в Сети бурно обсуждается офлайновая протестная деятельность природоохранной направленности. На горе Куштау в Башкирии с 3 августа 2020 г. проходят активные протесты. Дело в том, что Башкирская содовая компания начала вырубать лес вокруг горы для геологоразведки. Активисты экологических движений пытались и пытаются отбить гору, не пускают на нее тяжелую технику. Этот конфликт получил федеральную огласку и стал резонансным. Соответственно, в Сети идет активное обсуждение ситуации на Куштау. Онлайн-дискуссии шли и идут на разных сетевых площадках [25].

Спор же в социальных сетях о том, насколько значима дата 100-летия государственности для удмуртов, можно предложить в качестве темы для дальнейшего и отдельного обсуждения вместе с краеведами, со специалистами в сфере финно-угроведения и других (смежных) дисциплин.

Наряду с неизбежной дифференциацией участников сетевых дискуссий по гендерным или этническим признакам происходит различение и по возрастным характеристикам. Неизбежны здесь стереотипы, штампы и некоторая предвзятость. Ярким примером этого является «Методическое пособие по выявлению признаков риска поведения в социальных медиа», созданное АО «Крибрум».

Основатели компании «Крибрум» - Игорь Ашманов и Наталья Касперская. Судите сами, по мнению авторов этой методички, признаками деструктивного поведения являются пирсинг, наушники и принт «Нечего терять». Достаточно ли этих признаков, чтобы считать поведение молодежи деструктивным? [21; 26]. При этом Н. Касперская очень широко известна в ИКТ-среде. Согласятся ли с ее мнением специалисты по организации работы с молодежи? И если согласятся, то все ли?

Примеров подобных и совершенно других дискуссий очень много. Читатели и критики с легкостью назовут еще десяток злободневных тем сетевых медиакоммуникаций. Не имеет смысла и пытаться составить всеохватный список всех даже массовых дискуссий по различным поводам. Краткое же перечисление некоторых более или менее злободневных тем приводилось лишь для иллюстрации того, как не использовавшаяся в данном контексте абстрактная мультифрактальная модель может быть применимой для конструирования сетевых медиакоммуникаций в информационной цивилизации.

Вместе с этим приведенные примеры обсуждения проблем идентичности в Сети непосредственно связаны с методологией мультфрактального анализа сетевых медиакоммуникаций, поскольку соответствуют поисковым запросам по различным ключевым словам, характеризующим актуальные социально-экономические, политические, лингвистические, гносеологические или образовательные проблемы, а также вопросы этничности, идентичности в философии, психологии, антропологии и культурологии, в различных субкультурах и цивилизациях. Это верно как для сетевых медиакоммуникаций, так и для вполне научных массмедиа. В частности, в этом отношении С. Брэдфорд уточнил закон Зипфа. 
Мультифрактальность сетевых медиакоммуникаций в информационной цивилизации...

Брэдфорд утверждал, что если различные информационные ресурсы, например научные журналы, «расположить в порядке убывания числа статей по конкретному вопросу, то журналы в полученном списке можно разбить на три зоны таким образом, чтобы количество статей в каждой зоне по заданному предмету было одинаковым. При этом первую зону, так называемую зону ядра, будут составлять профильные журналы, непосредственно посвященные рассматриваемой тематике. Количество профильных журналов в зоне ядра невелико. Вторую зону образуют журналы, частично посвященные заданной области, причем число их существенно возрастает по сравнению с числом журналов в ядре. Третья зона, самая большая по количеству изданий, объединяет журналы» [14. С. 24] с самой многообразной тематикой, даже далекой от исходного вопроса.

В целом же мультифрактальная структура глобальных, субглобальных, национальных, региональных или локальных сетевых обсуждений, а также научных дискуссий в печатных научных СМИ по проблемам самоидентичности конструируется в ходе изменения, замены и усложнения разных моделей и алгоритмов самоорганизации нескольких (или многих) фракталоподобных древовидных массовых обсуждений.

На самом деле с точки зрения конструктивистской философии повседневности в современных медиакоммуникациях реализуется своего рода конструирование социальной реальности (почти по П. Бергеру и Т. Лукману).

При этом социальные сети стали не только независимой ареной для дискуссий или своеобразным фильтром и селектором информации, но и медиатором [5. С. 154], и мощным средством самоорганизации масс. Их возможности и потенциальные риски столь велики, что дальнейшие междисциплинарные исследования теории и практики в этой сфере просто необходимы.

\section{Некоторые перспективы дальнейшего изучения проблемы}

В обсуждении и анализе заявленной темы неизбежны переосмысление, критика и творческое развитие новых подходов.

Например, Д.В. Дунас на основе классического примера фрактального объекта (канторовского множества) фактически критикует новый подход, когда моделирует «схему прерванного коммуникативного акта массовой коммуникации». Но «в случае со вторым уровнем медиакоммуникации - межличностным - фрактальное описание не сработает. Принцип разорванности отрезков по принципу канторовского множества применим, когда мы говорим об однонаправленности и раздробленности коммуникационных потоков» [6. С. 92], по его мнению.

Однако против такого поспешного отказа от фрактального описания найдется несколько контраргументов. Во-первых, принцип разорванности отрезков по принципу канторовского множества является лишь одним из многих примеров фрактальных множеств.

Во-вторых, наряду с фрактальным описанием и/или вместо него можно использовать описание фракталоподобных структур (конечных, в отличие от бесконечных фрактальных структур).

В-третьих, для интеграции этих двух уровней медиакоммуникации (межличностной и массовой) в полисубъектном подходе фрактальное описание работает достаточно эффективно, по крайней мере в сфере научных медиакоммуникаций.

«Если закон Зипфа характеризует многие явления социального и биологического характера, то закон Брэдфорда - это специфический случай распределения Зипфа для системы периодических изданий по науке и технике, из которого можно извлечь выводы огромной практической пользы. С одной стороны, наблюдается концентрация значительного количества статей по определенной тематике в нескольких профильных журналах, с другой - рассеяние этих статей в огромном количестве изданий по смежной (или далекой от рассматриваемой) тематике. Существующее рассеяние публикаций нельзя оценивать только как вредное явление. В условиях рассеяния улучшаются возможности для межотраслевого обмена информацией, а значит, и для научных коммуникаций. Попытка сконцентрировать все публикации одного профиля в нескольких журналах, т. е. не допустить их рассеяния, будет иметь отрицательные последствия...» [14. С. 25].

Далее, самоорганизация и трансформация социальных систем фракталоподобных сетевых медиакоммуникаций определяют одну из коммуникативных перспектив развития современного общества. Кривая роста числа сообщений в сетевых медиакоммуникациях может быть описана экспоненциальной функцией, по крайней мере на некоторых этапах (в отсутствие войн и глобальных катастроф). 


\section{Заключение}

В целом мультифрактальность не противоречит основам разработки философской теории глобальных сетевых медиакоммуникаций, которая может быть фракталоподобной. Однако фракталоподобность философской теории глобальных сетевых медиакоммуникаций пока носит метафорический характер. Более подробное рассмотрение фракталоподобных перспектив философской теории глобальных сетевых медиакоммуникаций выходит за узкие рамки данной статьи и требует более масштабного дополнительного исследования.

В частности, в эту теорию впишутся кризис идентичности и проблема идентификации «чужих» и «своих», по крайней мере в некоторых регионах, и возможность возрождения или преобразования классовой идентичности (например, по проблемам изменения статуса интеллигенции, снижения роли пролетариата, размывания среднего класса и т. д.).

\section{СПИСОК ЛИТЕРАТУРЫ}

1. Ворсобин В. Зачем русских учить не по-русски. URL: https://www.kazan.kp.ru/daily/26720.5/3745927/?seealso.number=4645\#see-also (дата обращения: 25.05.2020).

2. Группа «ПРиИСК». URL: www.vk.com/priisc (дата обращения: 18.08.2020).

3. Группа «Удмуртия». URL: https://www.facebook.com/groups/udmurtia/ (дата обращения: 18.08.2020).

4. Группа Novosibirsk State University (NSU). URL: https://www.facebook.com/groups/124552334269354/members/ (дата обращения: 18.08.2020).

5. Дроздова А.В. Социальные медиа: между демократизацией и коммодификацией // Человек и мир: психология риска, инноваций, конфликта: сборник научных трудов. Екатеринбург: Издательство «Гуманитарный университет», 2016. C. 152-156. URL: https://www.elibrary.ru/item.asp?id=27555990 (дата обращения: 03.04.2020).

6. Дунас Д.В. Влияние антропологического фактора на теорию массовой коммуникации // Вестник МГУ. Сер. 10. Журналистика. 2009. № 1. С. 80-94.

7. Индийский вестник (Бюллетень посольства Индии в РФ). 2020. Март. 24 с.

8. Каримов Р.Н. От линейных моделей коммуникаций к сетевым - эволюция и синтез [Электронный ресурс] // Гуманитарные ведомости ТГПУ им. Л.Н. Толстого. 2018. № 3 (27). Т. 1. С. 161-172. URL: https://www.elibrary.ru/ item.asp?id=36508234 (дата обращения: 19.02.2020).

9. Кастельс М. Галактика Интернет: размышления об Интернете, бизнесе, обществе. Екатеринбург: У-Фактория, 2004. $328 \mathrm{c}$

10. Кемеров В.Е. Общество, социальность, полисубъектность. М.: Академический проект, 2012. 252 с.

11. Латыпов И.А. О мультифрактальности сетевых медиакоммуникаций в ЕС и РФ: социально-теоретический аспект // Актуальные тенденции социальных коммуникаций: история и современность: сб. науч. ст. (Материалы Международной научно-практической конференции «Актуальные тенденции социальных коммуникаций: история и современность», 29 октября 2018 г., Ижевск) / под ред. Г.В. Мерзляковой, Л.В. Баталовой, С.А. Даньшиной, О.В. Меншатовой, Е.И. Михалевой. Ижевск: Изд. центр «Удмуртский университет», 2018. C. 13-18. URL: https://elibrary.ru/item.asp?id=36754727 (дата обращения: 18.08.2020).

12. Латыпов И.А. Полисубъектная мультифрактальность информационных отношений в Сети: философские аспекты // Вестник Гуманитарного университета. Екатеринбург, 2014. № 4 (7). С. 80-87. ISSN 2308-8117.

13. Латыпов И.А. Фрактальность рекурсивной сети информационно-коммуникационных отношений // Актуальные тенденции социальных коммуникаций: история и современность: сб. науч. ст. Ижевск, 2013. С. 149-152.

14. Латыпов И.А., Латыпова Н.В. Логико-математический аппарат научных коммуникаций // Наука Удмуртии. Ижевск, 2016. № 3. С. 14-29.

15. Латыпова Н.В. Компьютерная обработка данных. Фракталы. Ижевск: Изд-во Удмуртский университет, 2012. $78 \mathrm{c}$.

16. Луман Н. Реальность массмедиа. М., 2005. 256 с.

17. Маклюэн М. Галактика Гутенберга: Становление человека печатающего. М., 2005. 496 с.

18. Нераскрытое наследие Великого Евразийца. [Электронный ресурc]. URL: https://www.gumilev-center.ru/ neraskrytoe-nasledie-velikogo-evrazijjca/ (дата обращения: 16.08.2020).

19. Савчук В.В. Медиафилософия. Приступ реальности. СПб., 2013. 350с.

20. Удмуртия [Электронный ресурс]. URL: https://ok.ru/group/52637594157126/https://ok.ru/nasha.udmurtia (дата обращения: 29.10.2020).

21. Цифровая гигиена [Электронный ресурс]. URL: https://d-russia.ru/wp-content/uploads/2019/03/tsifrovayagigiena.pdf (дата обращения: 29.10.2020).

22. Latypov I.A. Some fractal traits of Non-material (Spiritual) property: a philosophical aspect // International journal of applied and fundamental research. 2018. № 6. ISSN 1996-3955. [Электронный ресурс]. URL: http://www.science-sd.com/478-25409 (дата обращения: 18.08.2020). 
Мультифрактальность сетевых медиакоммуникаций в информационной цивилизации...

23. Mandelbrot B.B. A Multifractal Walk Down Wall Street. URL: https://www.scientificamerican.com/article/amultifractal-walk-down-wall-stree/ (дата обращения: 18.08.2020).

24. Youtube [Электронный ресурc]. URL: https://www.youtube.com/watch?v=Uvw Yv0F6FI\&feature= youtu.be\& fbclid=IwAR2S6b9PqZMwNKLdXipN57DdPQ-zkA7 Kq-GD7DnTKJU UpAqfyT1YisunA (дата обращения: 29.10.2020).

25.Zen (Yandex.Zen) [Электронный pecypc]. URL: https://zen.yandex.ru/media/tallis/ostorojno-molodej-s-aktivnoisocialnopoliticheskoi-poziciei-5e67e9f121e5616065dc9beb?fbclid=IwAR0djz4VFWui7ughzkmnBf4Zff4FftHcu NhHcXDaaSN8QD676gfhLVWtlpM (дата обращения: 29.10.2020).

Поступила в редакцию 19.09.2020

Латыпов Ильдар Абдулхаевич, доктор философских наук, доцент, профессор кафедры истории, теории и практики социальных коммуникаций ФГБОУ ВО «Удмуртский государственный университет» 426034, Россия, г. Ижевск, ул. Университетская, 1 (корп. 4) E-mail: ildarlatypov@mail.ru

\section{I.A. Latypov \\ MULTIFRACTALITY OF NETWORK MEDIACOMMUNICATIONS IN THE INFORMATION CIVILIZATION: PHILOSOPHICAL ASPECT}

DOI: $10.35634 / 2412-9550-2020-30-4-333-343$

The paper describes the philosophical context of multifractal characteristics of network mediacommunications development trends.

The analysis of these trends shapes the contours of new subject field of not only socio-philosophical or cultural studies, but also inter-disciplinary researches of the multifractality phenomenon as a whole.

Consideration of the multifractal prospects from the point of view of social philosophy of culture of an informational society is a kind of inter-disciplinary research in a sphere of philosophical works.

The paper forms a discourse of the multifractal mediacommunications in a global networking space. Mediacommunications in this research are defined as a kind of social communications in a media sphere. The main problem of the research may be reduced to the question: is it possible to characterize the issue of multifractality of network mediacommunications in a philosophical context?

The purpose of the research is the analysis of the philosophical aspect of multifractality of network mediacommunications in the information civilization.

The object of study is a variety of processes of social communications development connected to the prospects of modern mediacommunications.

The main hypothesis formulated in the research is that elaboration of the philosophical theory of global networking mediacommunications may be of a fractal-like nature.

The concept of multifractality is defined as a process and result of designing complex self-similar structures based on the consistent use of several algorithms to create different fractals.

Keywords: fractal, multifractality, on-line communication, mediacommunications, philosophy, information civilization.

Received 19.09.2020

Latypov I.A., Doctor of Philosophy, Professor

Udmurt State University

Universitetskaya st., 1/4, Izhevsk, Russia, 426034

E-mail: ildarlatypov@mail.ru 